\title{
Implications of a Reduction in the Hemoglobin Target in Erythropoiesis-Stimulating Agent-Treated Hemodialysis Patients
}

\author{
Timothy V. Nguyen ${ }^{\mathrm{a}}$ David S. Goldfarb ${ }^{\mathrm{b}}$ \\ ${ }^{a}$ Arnold and Marie Schwartz College of Pharmacy and Health Sciences-Long Island \\ University and Mount Sinai Medical Center, and ${ }^{b}$ New York University School of Medicine \\ and Nephrology Section, NY Harbor Healthcare System, New York, N.Y., USA
}

\section{Key Words}

Anemia $\cdot$ Chronic kidney disease $\cdot$ Erythropoietin $\cdot$ Hemodialysis $\cdot$ Iron $\cdot$ Kidney failure

\begin{abstract}
Background: Patients treated with erythropoiesis-stimulating agents (ESAs) to a hemoglobin $(\mathrm{Hb})$ level $>12.0 \mathrm{~g} / \mathrm{dl}$ have increased risk of multiple complications, including death. The optimal $\mathrm{Hb}$ target for ESA use has not been established. We hypothesized that reducing the target $\mathrm{Hb}$ would prevent levels $>12 \mathrm{~g} / \mathrm{dl}$ and lead to significant cost savings. Methods: Our target $\mathrm{Hb}$ range was reduced to $9-11 \mathrm{~g} / \mathrm{dl}$ from 10-12 g/dl. Thirty-five chronic hemodialysis (HD) patients received erythropoietin (EPO) and intravenous iron from January to December 2009. Data analysis included: $\mathrm{Hb}$ level, EPO dose, transferrin saturation and ferritin levels. EPO was administered via subcutaneous injection weekly or twice weekly. Results: The mean monthly $\mathrm{Hb}$ level changed from 11.2 to $10.6 \mathrm{~g} / \mathrm{dl}$. The percentages of patients with mean $\mathrm{Hb}>10.0,12.0$ and 13.0 $\mathrm{g} / \mathrm{dl}$ were $82 \pm 6.5,10 \pm 5.6$ and $1.8 \pm 1.9 \%$, respectively. Weekly EPO dose decreased from 9,500 to 5,600 units, a $40 \%$ reduction per dose per patient and costs. The savings exceeded USD 60,000 per year for 35 patients. More than $80 \%$ of patients had transferrin saturation $>20 \%$ and ferritin $>200 \mathrm{ng} / \mathrm{ml}$ throughout the entire period. Conclusions: Lowering the target $\mathrm{Hb}$ range to $9-11 \mathrm{~g} / \mathrm{dl}$ in HD patients achieved quality anemia management, avoided values $>12.0 \mathrm{~g} / \mathrm{dl}$ and resulted in cost savings. A minimal reduction in quality of life and no change in cardiovascular morbidity or mortality would be expected. The study has important implications in the new American bundled reimbursement model.

Copyright $\odot 2011$ S. Karger AG, Basel
\end{abstract}




\section{Introduction}

Anemia is a frequent complication of chronic kidney disease (CKD) and if unmanaged can lead to severe consequences. Erythropoiesis-stimulating agents (ESA) are frequently employed in the management of CKD-induced anemia. ESAs are recombinant protein products intended to improve the outcome of CKD-related anemia [1]. However, treating patients with ESAs to higher hemoglobin $(\mathrm{Hb})$ targets is associated with an increased risk of adverse effects, including death [2-5]. In previous studies, mortality has been associated with rapid ESA dose increases and rapid rises in $\mathrm{Hb}$ levels [6]. There is controversy surrounding what the optimal target $\mathrm{Hb}$ level in CKD patients should be. The black box warning of the Food and Drug Administration (FDA) was not to exceed $\mathrm{Hb}$ level $>12 \mathrm{~g} / \mathrm{dl}$ in ESA-treated patients [7], whereas the National Kidney Foundation-Kidney Disease Outcome Quality Initiative Anemia Guidelines recommend a $\mathrm{Hb}$ target range from 11 to $12 \mathrm{~g} / \mathrm{dl}$ and not to exceed 13 $\mathrm{g} / \mathrm{dl}[8]$. (Recently the FDA issued a new guideline suggesting that ESAs be used only to reduce the frequency of transfusions [9].) Managing CKD-induced anemia to achieve a narrow target range is difficult due to $\mathrm{Hb}$ fluctuations. Recent data also suggest that the adverse effects associated with ESA treatment of CKD patients are dose dependent, with larger ESA doses, rather than the $\mathrm{Hb}$ target dose, being associated with mortality and adverse events $[2-4,6]$. ESAs are very expensive drugs and mismanagement of anemia associated with CKD can increase costs. We hypothesize that in the context of uncertainty about the optimal $\mathrm{Hb}$ target, reducing the target $\mathrm{Hb}$ range in ESA-treated patients would prevent $\mathrm{Hb}$ levels $>12$ $\mathrm{g} / \mathrm{dl}$ and at the same time lead to cost savings.

\section{Subjects and Methods}

After publication of the results of CHOIR [3] and CREATE [4] in 2006 and the issuance of FDA black box warnings in 2007, we lowered the $\mathrm{Hb}$ target range in our hemodialysis (HD) unit from 10-12 to 9-11 g/dl in late 2008. Our rationale was that the optimal $\mathrm{Hb}$ target was not established and that higher $\mathrm{Hb}$ targets were potentially unsafe. At the time of that decision, the results of TREAT were not yet available, but since we participated in the study, we were aware that the control group received rescue darbepoetin when hemoglobin fell $<9 \mathrm{~g} / \mathrm{dl}$, which seemed a reasonable strategy [5]. Although in our relatively small unit we could not determine the optimal $\mathrm{Hb}$ target, we thought we should err on the side of safety and reduce the target. After reviewing the effect of treatment of anemia in CKD patients on healthcare-related quality of life [10], we thought the benefit of higher Hb targets was relatively small given the potential risks. We monitored the effect of this change in policy though our sample size would not suffice to establish if the change would lead to superior results. The policy change and monitoring were applied to all patients and did not constitute a research program, and therefore review by the institutional review board was not required.

The facility is a Department of Veterans Affairs Medical Center located in New York City. Patient demographics include mostly males, many $>65$ years old, receiving chronic HD, with diabetes and hypertension being the leading causes of kidney failure. We prospectively collected and retrospectively reviewed and analyzed data for 35 chronic adult HD patients who received EPO and intravenous iron from January to December 2009. Data analyzed included: $\mathrm{Hb}$ levels, EPO dose, transferrin saturation and ferritin levels. EPO was administered, as before, via subcutaneous injection weekly or twice weekly [11]. Ferric gluconate was administered intravenously to maintain transferrin saturation $>20 \%$ and ferritin $>200 \mathrm{ng} /$ $\mathrm{ml}$. Iron was also given to some patients with ferritin $>500 \mathrm{ng} / \mathrm{ml}$ as per DRIVE (Dialysis Patients' Response to IV Iron with Elevated Ferritin) Study [12]. 
Fig. 1. Mean Hb levels in 2009.

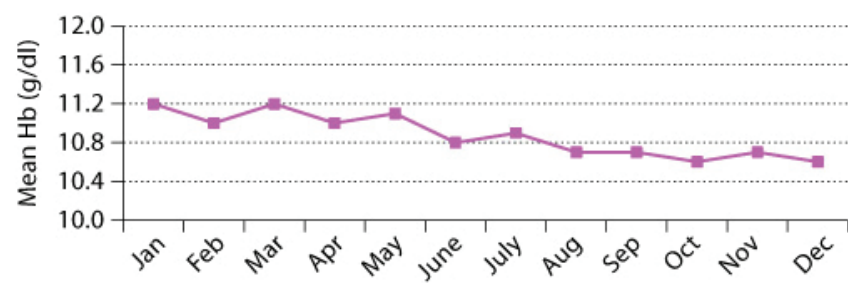

Fig. 2. Average EPO dose in units per week in 2009.

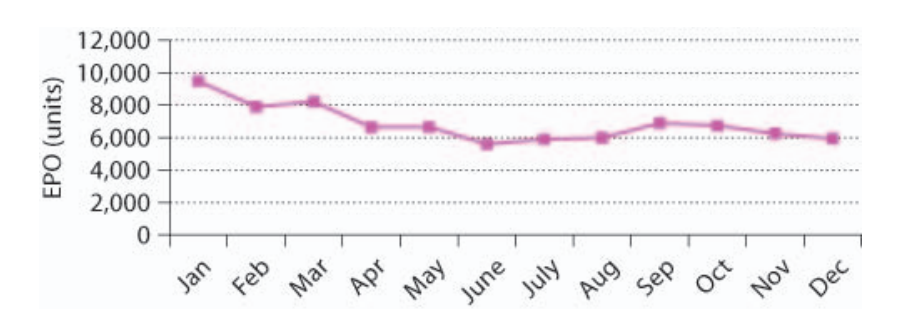

Table 1. Number of $\mathrm{Hb}$ determinations $>12.0$ and $>13.0 \mathrm{~g} / \mathrm{dl}$ in 2009 versus 2007

\begin{tabular}{llclll}
\hline & $\leq 12.0 \mathrm{~g} / \mathrm{dl}$ & $>12.0 \mathrm{~g} / \mathrm{dl}$ & $\leq 13.0 \mathrm{~g} / \mathrm{dl}$ & $>13.0 \mathrm{~g} / \mathrm{dl}$ & Total \\
\hline $\begin{array}{lllll}\text { Determinations of Hb, } \mathrm{n} \\
\quad\end{array}$ & & & & \\
In 2007 & 301 & $119^{*}$ & 382 & $38^{*}$ & 420 \\
In 2009 & 377 & 43 & 413 & 7 & 420 \\
$\quad$ Total & 678 & 162 & 795 & 45 & 840 \\
\hline
\end{tabular}

${ }^{*} \mathrm{p}<0.001$ vs. 2009 ( $\chi^{2}$ test $)$.

\section{Results}

The average 2009 monthly Hb levels fell from $11.2 \mathrm{~g} / \mathrm{dl}$ in January to $10.6 \mathrm{~g} / \mathrm{dl}$ in December. The percentage of patients with average monthly $\mathrm{Hb}$ in $2009>10.0,12.0$ and $13.0 \mathrm{~g} / \mathrm{dl}$ were $82 \pm 6.5,10 \pm 5.6$ and $1.8 \pm 1.9 \%$, respectively (fig. 1 ). The proportion of patients with values $>12.0$ and $>13.0 \mathrm{~g} / \mathrm{dl}$ was lower in 2009 compared with 2007 ( $\mathrm{p}<0.001, \chi^{2}$ test; table 1$)$. The average weekly EPO doses decreased from 9,500 in January to 5,600 units in December (fig. 2). The reduction was approximately $40 \%$ per dose per patient, which translated to a $40 \%$ reduction in costs of treatment. The savings exceeded USD 60,000 for 35 patients in 2009 or approximately USD 1,750 per patient per year based on the costs to the Department of Veterans Affairs of USD 182 for 20,000 units of EPO. More than $80 \%$ of patients had transferrin saturation $>20 \%$ and ferritin level $>200 \mathrm{ng} / \mathrm{ml}$ throughout the entire period.

\section{Discussion}

The management of CKD-induced anemia continues to have several controversial components: optimal $\mathrm{Hb}$ levels, ESA doses, potential adverse outcomes and costs. Clinicians rely on various clinical practice guidelines to help guide anemia management. However, these 
guidelines utilize data that include observational trials and expert opinions [8]. The most effective $\mathrm{Hb}$ target in patients with $\mathrm{CKD}$ remains to be determined and there is little evidence to support higher target $\mathrm{Hb}$ levels without the risks associated with ESAs. We revised the anemia guideline in our HD unit in order to address concerns about ESA utilization.

Prior to 2009, patients were treated with ESAs to a target $\mathrm{Hb}$ range of 10-12 g/dl, as recommended by the FDA anemia guidelines. This relatively narrow range and $\mathrm{Hb}$ variability led to many patients $(38 \pm 11.5 \%$ in December 2008) occasionally having Hb levels $>12$ $\mathrm{g} / \mathrm{dl}$. Of those that had $\mathrm{Hb}$ levels $>12 \mathrm{~g} / \mathrm{dl}(28 \pm 8.5 \%), 10 \pm 3 \%$ of patients had Hb levels $>13 \mathrm{~g} / \mathrm{dl}$. Due to these high percentages of patients achieving $\mathrm{Hb}>12 \mathrm{~g} / \mathrm{dl}$ levels, we revised the target $\mathrm{Hb}$ range to $9-11 \mathrm{~g} / \mathrm{dl}$. By reducing the $\mathrm{Hb}$ target, we hoped to decrease the number of patients having $\mathrm{Hb}$ levels raised $>12 \mathrm{~g} / \mathrm{dl}$.

The data demonstrate that by reducing Hb levels to 9-11 $\mathrm{g} / \mathrm{dl}$, we decreased the chance of having $\mathrm{Hb}$ levels rise to values $>12 \mathrm{~g} / \mathrm{dl}$ (fig. 1). At the same time, there was a decrease in ESA usage: from January to December 2009, the average EPO dose per week decreased from 9,500 to 5,600 units. This result yielded an approximately $40 \%$ reduction in ESA usage per dose per week. In 2009, we saved more than USD 60,000 for the approximately 35 patients we cared for.

Reducing the cost of treatment with ESAs is extremely important as the Center for Medicare and Medicaid Services (CMS) is moving toward a bundled reimbursement structure. The anticipated bundling of intravenous drugs including ESAs and intravenous iron into the dialysis composite rate is likely to lead to reductions in ESA utilization [11]. Given the results of TREAT [5], it is likely that reductions in $\mathrm{Hb}$ targets will be recommended by Kidney Disease: Improving Global Outcomes, CMS and FDA [12,13]. The CMS is also looking at performance measures to ensure that ESA-treated patients achieve high-quality anemia management and the risk associated with adverse events linked to higher Hb levels and ESA doses is decreased. According to the FDA, patients treated with ESAs should be closely monitored and have their $\mathrm{Hb}$ levels cautiously raised to avoid transfusion [9].

In patients with CKD, estimating the ESA dose that is both safe and effective in maintaining adequate $\mathrm{Hb}$ levels is challenging. Our study demonstrates that $\mathrm{CKD}$ patients on average required EPO doses $<10,000$ units per week and that approximately $82 \pm 6.5 \%$ of patients achieve $\mathrm{Hb}$ levels $>10 \mathrm{~g} / \mathrm{dl}$. Our findings are important in the light of previous findings that keeping ESA dose equivalents $<16,000$ units per week may decrease the risk of mortality in HD patients. A benefit of weekly doses $>16,000$ units has not been demonstrated [14]. The National Kidney Foundation also recognizes the importance of individualizing the treatment of anemia. The treatment target should not be based on $\mathrm{Hb}$ level alone, but should carefully consider the individual patient's clinical status. In general, patients with CKD should maintain a target $\mathrm{Hb}$ concentration to avoid blood transfusion. The exact target $\mathrm{Hb}$ concentrations should be tailored to the patient's need, gender, age, ethnicity, activity and co-morbid conditions. Treatment with ESAs has improved patients' lives. However, recent studies have found that higher $\mathrm{Hb}$ targets cause harm. Practitioners have realized the value of ESAs in the management of anemia, but the high cost and new safety concerns should remind practitioners to reexamine ESA use $[9,15]$.

Our study is not without limitations. Outcomes were analyzed retrospectively and we used administrative data from a single dialysis center. We did not track iron utilization but administered iron per protocol to all patients to ensure that iron deficiency, whether absolute or functional, was not present [12]. We would predict that cumulative doses and costs associated with iron administration were lower with the lower $\mathrm{Hb}$ target, further contributing to the economic benefit. Hb variability and ESA dosing could be associated with other underlying patient characteristics. We cannot establish whether reducing the $\mathrm{Hb}$ target is associated with higher or lower mortality rates, with prevention of left ventricular hypertrophy or with reductions in health-related quality of life. 


\section{Conclusion}

Treating patients with ESAs to higher $\mathrm{Hb}$ targets is associated with an increased risk of adverse effects, including death. Lowering the target $\mathrm{Hb}$ range to 9-11 $\mathrm{g} / \mathrm{dl}$ in $\mathrm{HD}$ patients treated with EPO achieved quality anemia management with significantly fewer numbers of patients with a dangerous $\mathrm{Hb}$ rise $>12 \mathrm{~g} / \mathrm{dl}$ and at the same time resulted in cost savings.

\section{Disclosure Statement}

Dr. Goldfarb is a consultant for Takeda.

\section{References}

1 Aranesp (darbepoetin alfa) package insert. Thousand Oaks, Amgen, 2002.

2 Besarab A, Bolton WK, Browne JK, et al: The effects of normal as compared with low hematocrit values in patients with cardiac disease who are receiving hemodialysis and epoetin. $\mathrm{N}$ Engl J Med 1998;339:584-590.

3 Singh AK, Szczech L, Tang KL, et al: Correction of anemia with epoetin alfa in chronic kidney disease (CHOIR). N Engl J Med 2006;355:2085-2098.

4 Drueke TB, Locatelli F, Clyne N, et al: Normalization of hemoglobin level in patients with chronic kidney disease and anemia (CREATE). N Engl J Med 2006;355:2071-2084.

5 Pfeffer MA, Burdmann EA, Chen CY, et al: A trial of darbepoetin alfa in type 2 diabetes and chronic kidney disease (TREAT). N Engl J Med 2009;361:2019-2032.

6 Lau JH, Gangji AS, Rabbat CG, Brimble KS: Impact of hemoglobin and erythropoietin dose changes on mortality: a secondary analysis of results from a randomized anemia management trial. Nephrol Dial Transplant 2010;25:4002-4009.

7 US Food and Drug Administration: Postmarketing drug safety information for patients and providers. Approved Risk Evaluation and Mitigation Strategies (REMS). www.fda.gov/drugs/drugsafety/ postmarketdrugsafetyinformationforpatientsandproviders/ucm109375.htm (accessed December 13, 2010).

8 National Kidney Foundation. KDOQI Clinical Practice Guidelines and Clinical Practice Recommendations for Anemia in Chronic Kidney Disease. Am J Kidney Dis 2006;47(suppl 3):S1-S146.

9 Erythropoiesis-Stimulating Agents (ESAs) in Chronic Kidney Disease: Drug Safety Communication - Modified Dosing Recommendations. http://www.fda.gov/Safety/MedWatch/SafetyInformation/ SafetyAlertsforHumanMedicalProducts/ucm260641.htm (accessed June 24, 2011).

10 Leaf DE, Goldfarb DS: Interpretation and review of health-related quality of life data in CKD patients receiving treatment for anemia. Kidney Int 2009;75:15-24.

11 Kaufman JS, Reda DJ, Fye CL, Goldfarb DS, et al: Subcutaneous compared with intravenous epoetin in patients receiving hemodialysis. Department of Veterans Affairs Cooperative Study Group on Erythropoietin in Hemodialysis Patients. N Engl J Med 1998;339:578-583.

12 Coyne DW, Kapoian T, Suki W, et al: Ferric gluconate is highly efficacious in anemic hemodialysis patients with high serum ferritin and low transferrin saturation: results of the Dialysis Patients' Response to IV Iron with Elevated Ferritin (DRIVE) Study. J Am Soc Nephrol 2007;18:975-984.

13 H.R. 6331: Medicare Improvements for Patients and Providers Act of 2008. http://www.govtrack.us/ congress/bill.xpd?bill=h110-6331 (accessed December 26, 2010).

14 Kainz A, Mayer B, Kramar R, Oberbauer R: Association of ESA hypo-responsiveness and haemoglobin variability with mortality in HD patients. Nephrol Dial Transplant 2010;25:3701-3706.

15 Medicare Program; Changes to the End-Stage Renal Disease Prospective Payment System for CY 2012, End-Stage Renal Disease Quality Incentive Program for PY 2013 and PY 2014; Federal Register/ vol. 76, No. 131/Friday, July 8, 2011/Proposed Rules. http://www.gpo.gov/fdsys/pkg/FR-2011-07-08/ pdf/2011-16874.pdf (accessed August 1, 2011). 